\title{
LGBTFOBIA EM ÂMBITO ESCOLAR E SUAS INTERFERÊNCIAS NO PROCESSO DE APRENDIZAGEM: MAPEANDO A LGBTFOBIA NOS INSTITUTOS FEDERAIS DO RIO GRANDE DO NORTE
}

\section{LGBTFOBIA AND THEIR INTERFERENCES IN THE LEARNING PROCESS: MAPPING LGBTFOBIA IN THE FEDERAL INSTITUTE OF RIO GRANDE DO NORTE}

Jeam Claude de Souza Gomes ${ }^{1}$; Rebecka de França²; José Carlos da Silva Junior ${ }^{3}$; João Paulo Teixeira Viana ${ }^{4}$; Maria Cristina Cavalcanti de Araújo ${ }^{5}$

\section{INTRODUÇÃO}

Sem dúvidas, o silenciar da escola pela falta de práticas pedagógicas e a ausência de políticas públicas que combatam ou minimizem os efeitos da LGBTfobia no âmbito escolar, contribuem para institucionalizar uma violência que por mais que se queira esconder, tem sido cada vez mais visível no ambiente escolar. Charles Radcliffe (2015) ao discutir a temática afirma que apesar dos jovens carregarem consigo uma gama de preconceitos que muitas vezes são adquiridos na família, por influência de amizade ou da mídia, estes preconceitos precisam ser desconstruídos, e o melhor ambiente para isso é a escola.

Lugar das diferenças e da pluralidade de pensamentos. Radcliffe (2015) comenta ainda que muitas vezes "crianças podem aprender atitudes homofóbicas com seus pais, mas as escolas devem fazer todo o possível para combater os estereótipos negativos e promover a aceitação". A escola é lugar de mediar conflitos e superá-los.

Nesse sentido, o presente trabalho se justifica pelo grande número de casos de LGBTfobia nas escolas, e tem como objetivo geral expor as interferências da LGBTFOBIA no processo de aprendizagem de alunos do ensino médio em especial os do IFRN, onde ao final da pesquisa será construído um mapa com o ranking dos casos de violência contra a população LGBT na escola.

\section{FUNDAMENTAÇÃO TEÓRICA}

Compreendendo-se que a escola é um espaço de todos, deve sempre estar aberta ao diálogo, incitando o pensamento crítico e a reflexão sobre a realidade social na qual está inserida, como uma comunidade democrática deve agregar a todos os setores sociais nas mais

\footnotetext{
${ }^{1}$ Licenciatura em Geografia, IFRN, jeanclaude.14@ hotmail.com

${ }^{2}$ Licenciatura em Geografia, IFRN, atransparenciarn@ outlook.com

${ }^{3}$ Licenciatura em Geografia, IFRN, josecarlossilvajr6@gmail.com

${ }^{4}$ Licenciatura em Geografia, IFRN, jpviana25@yahoo.com

${ }^{5}$ Doutora, IFRN, cristina.cavalcanti@ifrn.edu.br
} 

diversas discussões.

Sendo assim evitar falar na escola sobre gênero ou LGBTfobia, é uma forma de se institucionalizar o preconceito, independentemente da percepção ou da não existência de casos dentro das instituições escolares. A omissão destas discussões fortalece a ignorância e preservar o preconceito além de perpetuar a invisibilidade. Dessa forma Louro afirma:

Ao não falar a respeito deles e delas, talvez se pretenda eliminá-los, ou, pelo menos, se pretenda evitar que os alunos e as alunas 'normais' os/as conheçam e possam desejá-los/as. Aqui, o silenciamento - a ausência da fala - aparece como uma espécie de garantia da "norma". (LOURO,1997, p. 67).

As instituições de ensino têm se tornado um ambiente onde os casos de LGBTfobia tem crescido a cada segundo. Teixeira (2011, p.26-27) ressalva que dentre essas práticas as mais comuns são: "xingar, ameaçar, amedrontar, intimidar, humilhar, hostilizar, ofender, excluir, difamar, assediar, abusar, gritar, bater, chutar, empurrar, perseguir, violentar, apelidar, furtar ou danificar particulares de pessoas LGBTs ou entendidas como tal”. Diante desse quadro, tornase de fundamental importância que os movimentos LGBTs desenvolvam e reivindiquem ações junto ao Estado bem como políticas públicas de enfrentamento a LGBTfobia, em especial no ambiente escolar, onde o jovem LGBT infelizmente se depara com as primeiras situações de preconceito fora do espaço familiar e da comunidade em que está inserido o que ocasiona vários danos, entre eles, afetar diretamente os processos de aprendizagem e convívio social.

É importante diferenciar uma possível entre o que é violência e brincadeiras típicas da adolescência. Neste sentido, Fante apud pedra (2008) em seus estudos afirmar: que os critérios estabelecidos constituem: ações reiteradas em depreciação da mesma pessoa num longo período de tempo; desproporção de poder entre agressor e agredido; e ausência de causa ou motivação aparente que expliquem as agressões (apud FANTE; PEDRA, 2008).

Dessa maneira, nem sempre há vontade por parte do estudante para denunciar tais situações para a gestão da escola devido a uma série de fatores como: vergonha, confiança, medo, ou por temer represarias por parte dos agressores e até mesmo uma possível exposição do assunto dentro da escola. No entanto, é papel da escola intermediar conflitos, dentre eles, os que envolvem a LGBTfobia.

\section{METODOLOGIA}

Para atingir os objetivos propostos, será aplicada abordagem qualitativa e quantitativa através do mapeamento de casos de LGBTFOBIA nos institutos federais do RN, análise de documentos, artigos e obras relacionados à temática assim como também análise de entrevistas e questionários aplicados on-line e em visitas realizadas aos institutos. Depreende-se que a 
abordagem qualitativa, enquanto exercício de pesquisa, não se apresenta como uma proposta rigidamente estruturada, ela permite que a imaginação e a criatividade levem os investigadores a propor trabalhos que explorem novos enfoques, afirma Godoy (1995).

\section{RESULTADOS E DISCUSSÕES}

A aplicação de questionários eletrônicos iniciou-se no dia 01 de setembro, os questionários estão disponíveis na plataforma eletrônica do google formulários, até o presente momento a pesquisa alcançou um total de 340 alunos dos 21 campis do IFRN e de todas as modalidades de cursos. No primeiro momento procuramos analisar o perfil dos entrevistados através do gênero que se identifica e a faixa etária abaixo os resultados estão representados nos gráficos 01 e 02.

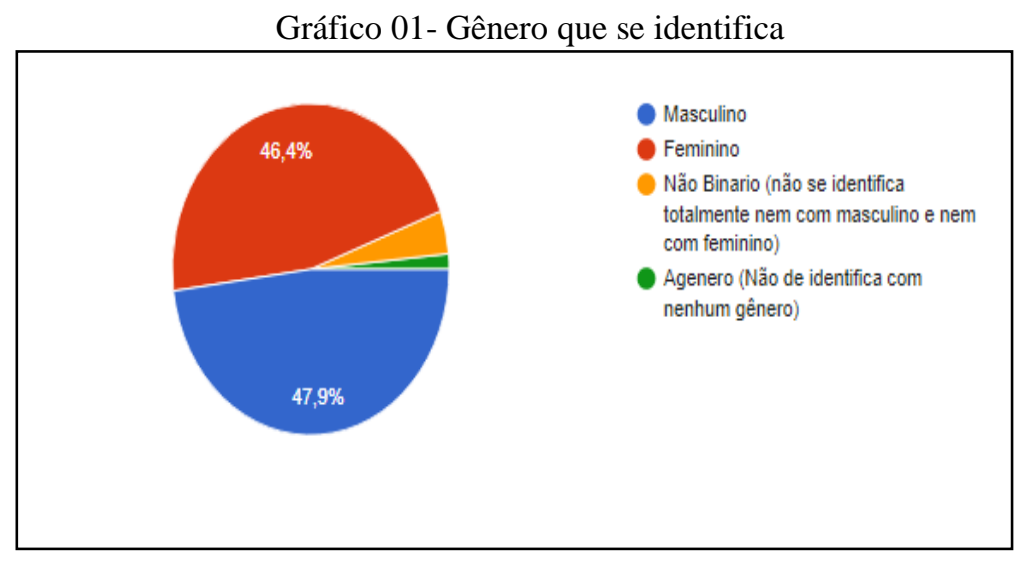

Fonte Própria

A maioria dos entrevista são do sexo masculino, 1,5\% agênero e 4,5\% não binário. $\mathrm{O}$ gráfico 02 retrata a faixa etária dos entrevistados. Percebemos que a maioria dos entrevistados são adolescentes, procuramos avaliar qual letra da sigla LGBTQI+ o entrevistado se identifica o resultado será apresentado no gráfico 03.

Gráfico 02- Idade Dos Entrevistados

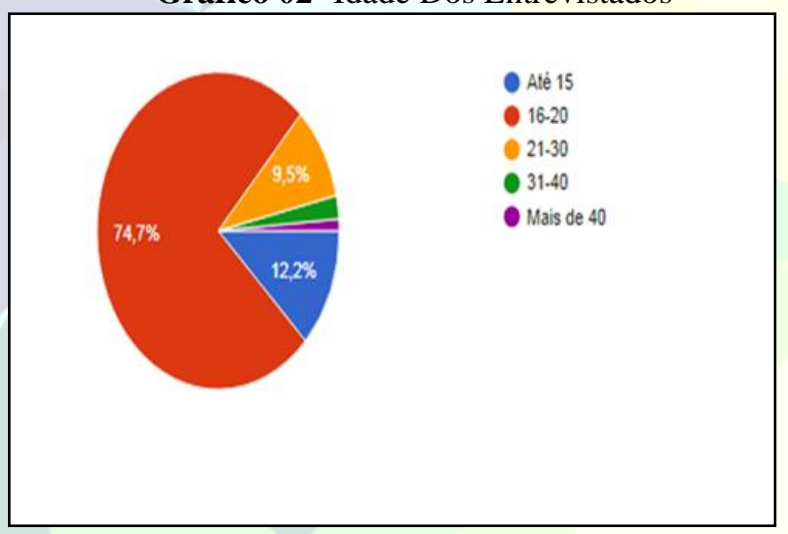

Fonte propria
Gráfico 03- Identificação com a sigla

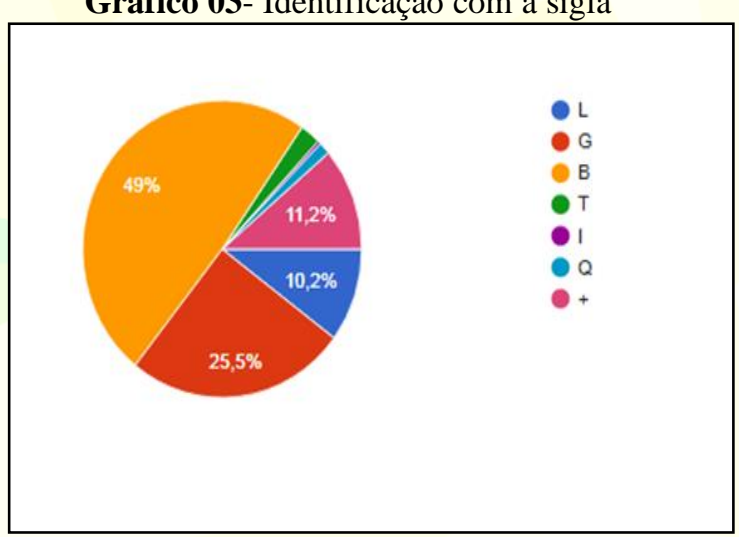

Fonte propria 
A grande maioria dos entrevistados se identificam como bissexual, o que não podemos ao certo afirmar se isso representa uma forma de esconder sua verdadeira orientação sexual. em seguida procuramos saber a qual campus o entrevistado pertence o resultado será apresentado no gráfico 04.

Gráfico 04- Campus do IFRN o entrevistado estuda

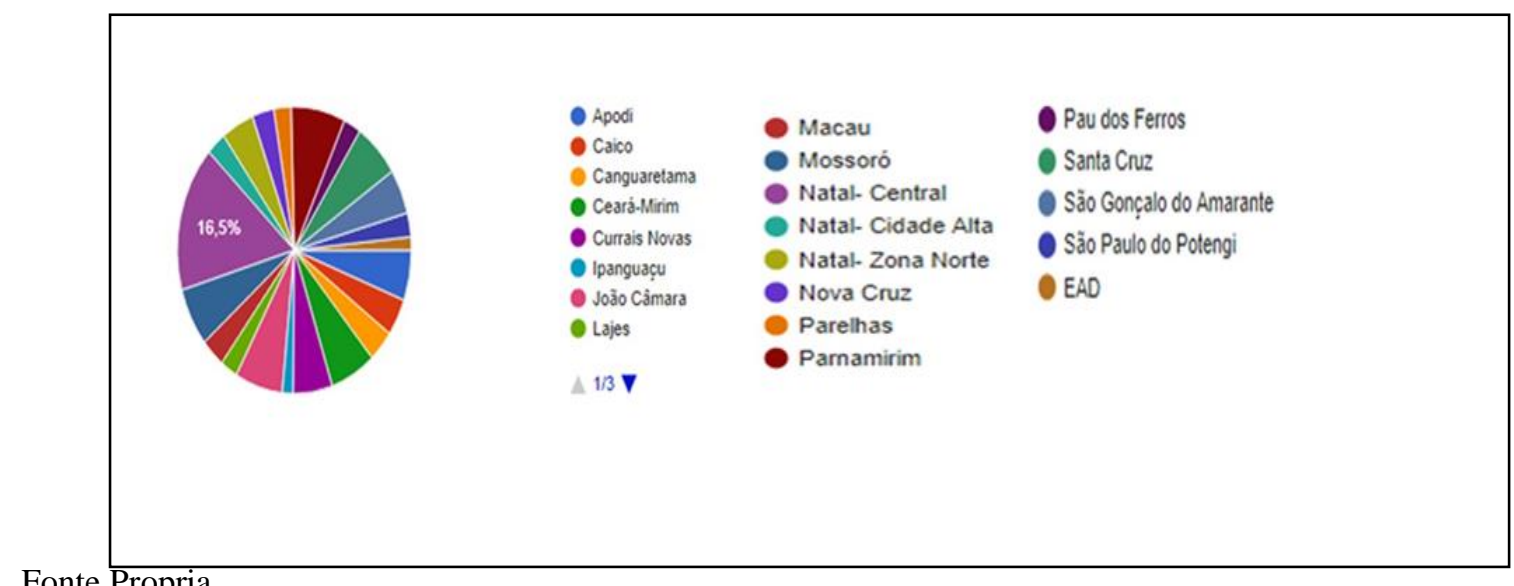

Umas das questões de grande relevância para o projeto que busca identificar se o aluno já sofreu algum tipo de violência dentro do IFRN por conta de sua orientação sexual o resultado será exposto a seguir no gráfico 05 .

Gráfico 05- Já Sofreu Algum Tipo de Violência por Causa de Sua Orientação Sexual/Identidade de Gênero no IFRN

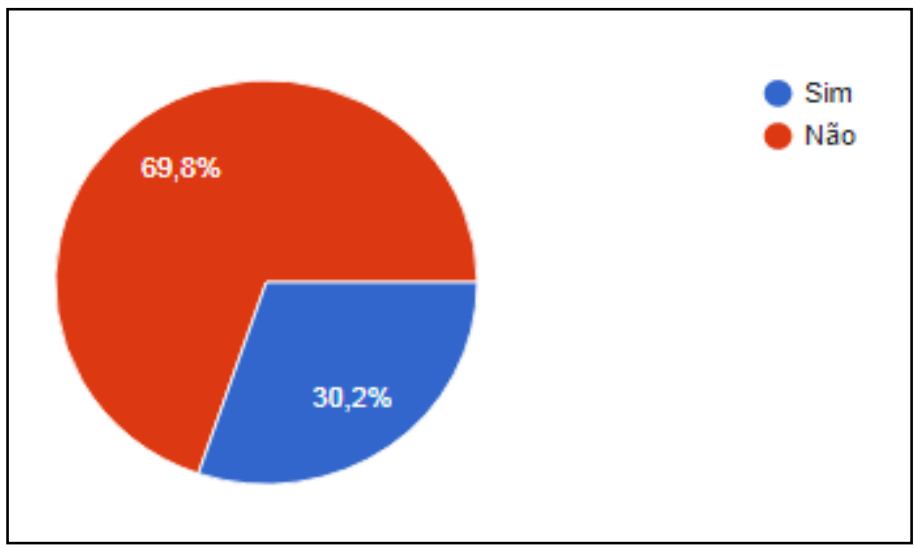

Fonte própria

Notamos que a minoria dos alunos que responderam ao questionário afirma ter sofrido LGBTFOBIA no IFRN, o que gera diversas reflexões, será que o IFRN tem se tornado cada dia mais uma instituição democrática, ou aquele que sofre com a LGBTFOBIA prefere se esconder com medo de retaliações? O que sabemos de fato é que a LGTFOBIA existe mesmo que para uma pequena parcela, e essa pequena parcela sofre diariamente com diversas formas de violência como exposto no gráfico 06. 
Gráfico 06 - Tipo de Violência

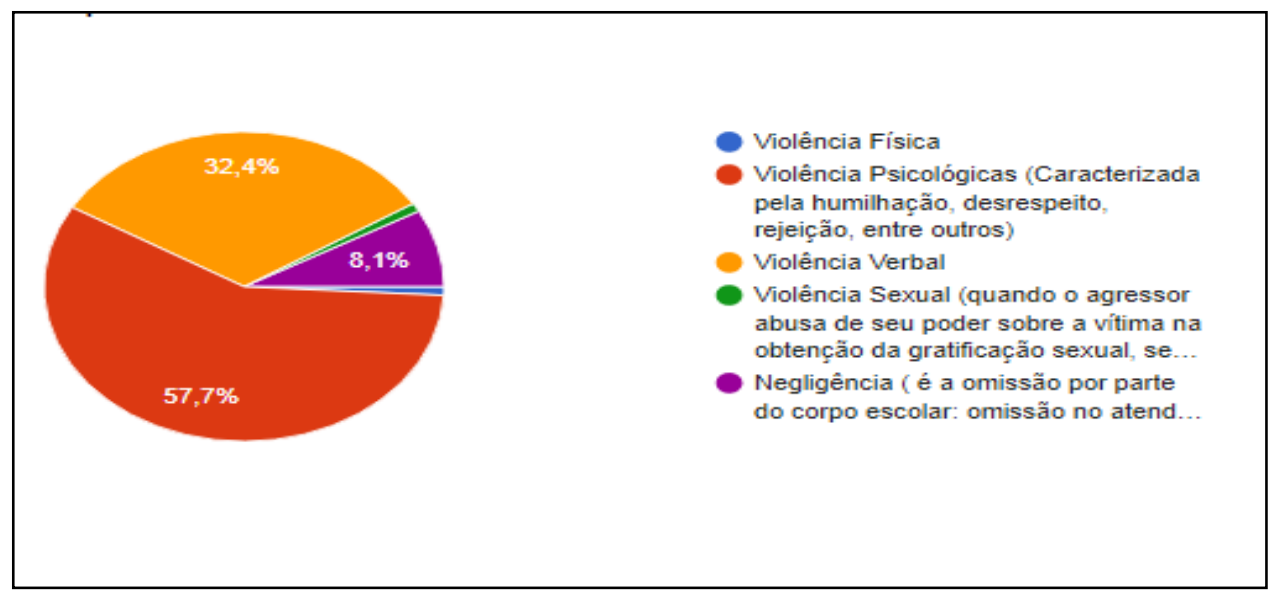

Fonte Própria

A partir desses elementos expostos a pesquisa busca identificar se esses alunos que sofreram com a lgbfobia, sentiu algum tipo de dificuldade no aprendizado $27 \%$ dos que sofrem com violência afirmam ter tido dificuldade de aprendizagem conforme o gráfico 07.

Gráfico 07- Dificuldade de aprendizagem por ter sofrido LGBTFOBIA

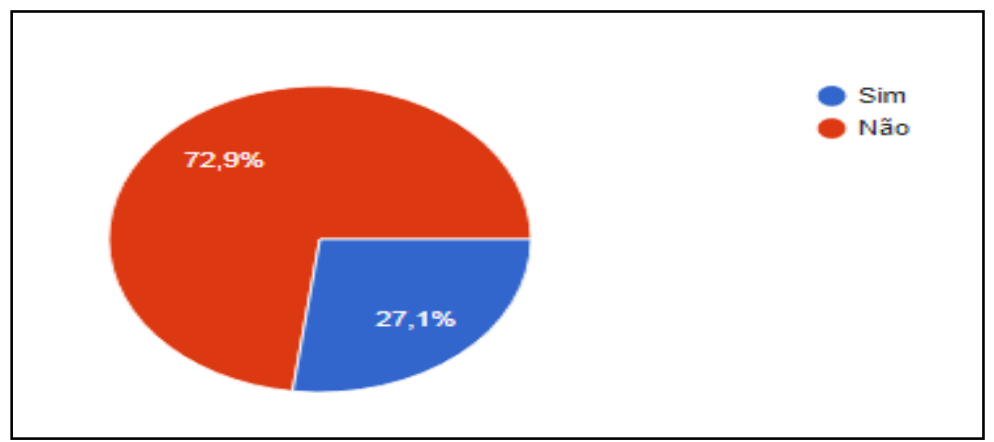

Fonte Própria

A pesquisa ainda encontra-se em andamento, porém percebemos que com os resultados já obtidos uma pequena parcela de alunos sofrem violência por expressarem sua orientação sexual.

\section{CONCLUSÕES}

A lgbtfobia tem crescido a cada ano no mundo, desta forma é preciso enfatizar a problemática para que ações sejam tomadas a fim de banir este tipo de violência, principalmente nas escolas. Depreende-se que, o projeto busca trazer à tona os casos de LGBTFOBIA nos campis do IFRN, identificado sua interferência no processo de aprendizagem do aluno.

\section{REFERÊNCIAS}

DAL-FARRA, Rossano André Paulo; LOPES, Tadeu Campos. Métodos Mistos de Pesquisa em Educação: pressupostos teóricos. Nuances: estudos sobre Educação, Presidente Prudente- 
SP, v. 24, n. 3, p. 67-80, set./dez. 2013. Disponível em: Acesso em: 22 mar. 2018.

FANTE, C.; PEDRA, J. A. Bullying escolar: perguntas \& respostas. Porto Alegre: Artmed, 2008.

LOURO, G. L. Gênero, sexualidade e educação: uma perspectiva pós-estruturalista. Petrópolis: Vozes, 1997.

RADCLIFFE, Charles. Chefe da seção de assuntos globais do escritório para direitos humanos da ONU em Nova York. Disponível em: <http://blogdosakamoto.blogosfera.uol.com.br/2015/08/06/escolas-devem-combaterhomofobia-que-vem-decasa-diz-especialista-da-onu/> Acesso em: 10 ago 2017.

TEIXEIRA, G. Manual antibullying: para alunos, pais e professores. Rio de Janeiro: BestSeller, 2011. 